\title{
"It Takes Two to Tango": understanding how centrosome duplication is regulated throughout the cell cycle
}

\author{
Edward H. Hinchcliffe ${ }^{1}$ and Greenfield Sluder ${ }^{2}$ \\ Department of Cell Biology, University of Massachusetts Medical School, Worcester, Massachusetts 01605, USA
}

The essence of successful mitosis is the generation of two genetically identical daughter cells. This requires the assembly of a strictly bipolar mitotic apparatus that will ensure that all daughter chromosomes are segregated to opposite sides of the cell before the completion of mitosis. The agent of the higher animal cell for the establishment of this essential "twoness" is the pair of centrosomes that organize the spindle poles during mitosis (Mazia 1987).

Before the cell enters mitosis, the single interphase centrosome duplicates or reproduces exactly once, and the daughter centrosomes form the two poles of the spindle after breakdown of the nuclear envelope. Failure of the cell to precisely control this duplication of the centrosome can have disastrous consequences. If the centrosome fails to duplicate before the onset of mitosis, most somatic cells eventually return to interphase without dividing, which causes polyploidy. If the centrosome duplicates more than once in a cell cycle, then a multipolar spindle may be assembled and the chromosomes may be unequally distributed to the daughter cells, leading to genetic imbalances that produce cells with aggressive growth characteristics (for reviews, see Orr-Weaver and Weinberg 1998; Brinkley 2001). In fact, the cells of many lethal human tumors are genetically unstable and have abnormally high numbers of centrosomes (Lingle et al. 1998; Pihan et al. 1998; Carroll et al. 1999|. Extra centrosomes are a problem because the condition is not remediated; cells do not have a checkpoint that aborts mitosis in response to extra spindle poles (Sluder et al. 1997). In this review, we focus on the mechanisms that control centrosome duplication and coordinate it with nuclear events during the cell cycle.

The structure and activities of the centrosome

At the ultrastructural level, the centrosome of a typical mammalian cell consists of a pair of centrioles associ-

\footnotetext{
${ }^{1}$ Present address: Department of Biological Sciences, University of Notre Dame, Notre Dame, IN 46556 USA

${ }^{2}$ Corresponding author.

E-MAIL Greenfield.sluder@umassmed.edu; FAX 508-856-8774.

Article and publication are at http://www.genesdev.org/cgi/doi/10.1101/ gad.894001.
}

ated with a cloud of electron dense material known as the pericentriolar material (PCM), which surrounds one or both centrioles depending on the cell type (for reviews of centrosome ultrastructure, see Stubblefield 1968; Wheatley 1982; Bornens et al. 1987; Vorobjev and Nadezhdina 1987; Palazzo et al. 2000; Preble et al. 2000). The centrioles themselves are a barrel of nine triplet microtubules $400 \mathrm{~nm}$ in length (Marshall and Rosenbaum 1999|. These stable microtubules are composed of a large number of polypeptides, including $\alpha / \beta / \delta / \varepsilon$ tubulin (Dutcher 2001) and centrin (Salisbury 1995), as well as tektin filaments and their associated structural proteins (Steffen et al. 1994; Hinchcliffe and Linck 1998). The PCM consists of a fibrous meshwork, known as the centromatrix (Schnackenberg and Palazzo 1999), that binds a variety of proteins, including the $\gamma$ tubulin ring complexes that nucleate microtubules (for reviews, see Wiese and Zheng 1999; Zimmerman et al. 1999). The PCM around the centrioles thus acts as the centrosomal microtubule-organizing center (MTOC), which nucleates the interphase microtubular array and essentially all the spindle microtubules during mitosis (Euteneuer and McIntosh 1981). The centrioles do not directly participate in the nucleation of cytoplasmic microtubules (Gould and Borisy 1977).

In many types of somatic cells, the centrosome moves during interphase to the cell cortex, and the older of the two centrioles nucleates the doublet microtubules of the primary cilium (Fulton 1971; Rieder and Borisy 1982; Wheatley 1982; Preble et al. 2000). In this respect, a centriole will act as a basal body, an organelle of closely similar ultrastructure found in high copy numbers in ciliated cells. Centrioles that organize primary cilia also have a number of attached accessory structures, such as conical projections on the exterior of their proximal ends, called basal feet, that have microtubules attached to their globular tips (Albrecht-Buehler and Bushnell 1980; Wheatley 1982; Preble et al. 2000). Presumably, these microtubules help anchor the flagellar apparatus to the cell.

Although they do not nucleate cytoplasmic microtubules, the centrioles serve to localize the pericentriolar material into a focal body and thus determine the num- 
ber of MTOCs present in the cell. Centrioles are rich in polyglutamylated tubulin, and the microinjection of antibodies raised against poly-glutamylated tublin into living human (HeLa) cells leads to the disassembly of the centrioles (Bobinnec et al. 1998). Concurrently, this leads to the scattering of the PCM and the disappearance of the centrosomal MTOC as a defined body in interphase. When the centrioles reform several hours later, the centrosomal MTOCs become focal again. That centrioles could have an activity that localizes the PCM can also be inferred from the finding that the PCM is not always equally distributed in the vicinity of both centrioles. For example, in rat kangaroo kidney epithelial cells (PtK cells), the PCM is primarily associated with the older of the two centrioles; the daughter centriole does not acquire PCM until it splits from its mother and assembles its own daughter (Rieder and Borisy 1982). Additional evidence that centrioles localize the PCM comes from the classic observation that polyspermic fertilization of sea urchin eggs leads to the formation of additional spindle poles (Wilson 1896). That this activity is specific to the centrioles is revealed by findings that the microinjection of isolated sperm centrioles into sea urchin zygotes or Xenopus zygotes leads to the formation of supernumerary asters in a dose-dependent fashion (Maller et al. 1976; Hirano 1982). Finally, when sea urchin zygotes are mechanically fragmented with a fine screen just after fertilization, the fragments that contain just a female pronucleus form a single aster at first mitosis that does not contain centrioles (Sluder et al. 1989). This occurs because the centrioles to be used in development are cut off, with the cytoplasm containing the sperm nucleus. As the cell fragment proceeds from one mitosis to the next, the aster does not double and becomes less and less focal at each mitosis. By the third mitosis, the microtubules often are highly disorganized. In sharp contrast, fragments containing just the male pronucleus assemble focal asters containing centrioles and repeatedly divide in a normal fashion.

\section{The role of the centrosomes in determining spindle polarity}

The number of centrosomes in a cell at the onset of mitosis typically determines the number of spindle poles. For both zygotes and somatic cells, those containing a single centrosome or an unseparated pair of centrosomes form a monopolar spindle at mitosis (Fig. 1; Bajer 1982; Sluder and Begg 1985). Cells that contain more than two centrosomes typically form a multipolar spindle, the polarity of which corresponds to the number of centrosomes interacting with the chromosomes (Fig. 1; Heneen 1975; Rieder et al. 1997; Sluder et al. 1997).

However, this "one centrosome, one spindle pole" notion is simplistic. Observations of bipolar spindle assembly in cells that lack centrosomes have revealed the existence of a second mechanism for spindle pole formation, even in cells that normally contain centrosomes (for review, see Compton 2000). Findings, some dating back almost 40 years, that male and female meiotic cells can form bipolar acentrosomal spindles challenged the notion that centrosomes are needed for the establishment of spindle bipolarity (Dietz 1966; Steffen et al. 1986). More recent work with Xenopus egg extracts has revealed that bipolar spindles will assemble from initially randomly oriented microtubules assembled in the vicinity of chromatin, be it chromosomes or beads coated with DNA fragments (Heald et al. 1996, 1997). Spindle organization is achieved through the bundling and movement of these microtubules into bipolar arrays by the action of microtubule-based motor proteins coupled with the bundling action of the nuclear mitotic apparatus protein (NuMa; Gaglio et al. 1997). Recently, these findings have been extended to somatic cells with the demonstration that after laser ablation of centrosomes during prophase, green monkey kidney epithelial cells expressing $\gamma$ tubulin-GFP (CVG-2 cells; Khodjakov et al. 1997) assemble a functional bipolar spindle (Khodjakov et al. 2000; Hinchcliffe et al. 2001; Khodjakov and Reider 2001). Together, these findings have raised the possibility that centrosomes are simply microtubule donors or are perhaps completely irrelevant for spindle pole formation. However, when observations of spindle assembly in a wide variety of dividing cells are considered together, one finds that the ability of a cell to form acentrosomal spindle poles is system dependent and that centrosomes, when present, act in a dominant fashion to determine spindle polarity (Heald et al. 1997). The alternative mechanism for bipolar spindle assembly is revealed only when centrosomes are not present. Thus, it appears that spindle pole formation in higher animal cells is the result of the cooperative action of two mechanisms: (1) the microtubule motor protein bundling/rearrangement of cytoplasmic microtubules, and (2) centrosomes.

To further complicate the story, the existence of stable cell lines in which many or all of the cells contain multiple centrosomes has challenged the notion that multiple centrosomes always produce a multipolar cell division. For example, mouse neuroblastoma (N115) cells and p53 ${ }^{-/-}$mouse embryo fibroblasts contain multiple MTOCs, each containing centrioles, yet they divide in a bipolar fashion, at least most of the time (Ring et al. 1982; Fukasawa et al. 1996). Similarly, one can ask how the cells of aggressive human tumors containing multiple centrosomes can propagate without catastrophic loss of chromosomes and consequent loss of viability (Lingle et al. 1998; Pihan et al. 1998; Caroll et al. 1999).

We submit that these observations do not necessarily constitute a challenge to the notion that the number of centrosomes determines spindle polarity in normal cells. These cells have undergone clonal selection for compensatory mechanisms that are able to deal with the presence of multiple centrosomes. Possibly these cells have up-regulated the levels of microtubule bundling proteins, such as $\mathrm{NuMa}$, so that the centrosomes are constrained from separating to form a multipolar spindle. In effect, the alternative mechanisms for spindle bipolarization, described above, now dominate. Indeed, the finding of an increase in genomic stability for populations of 

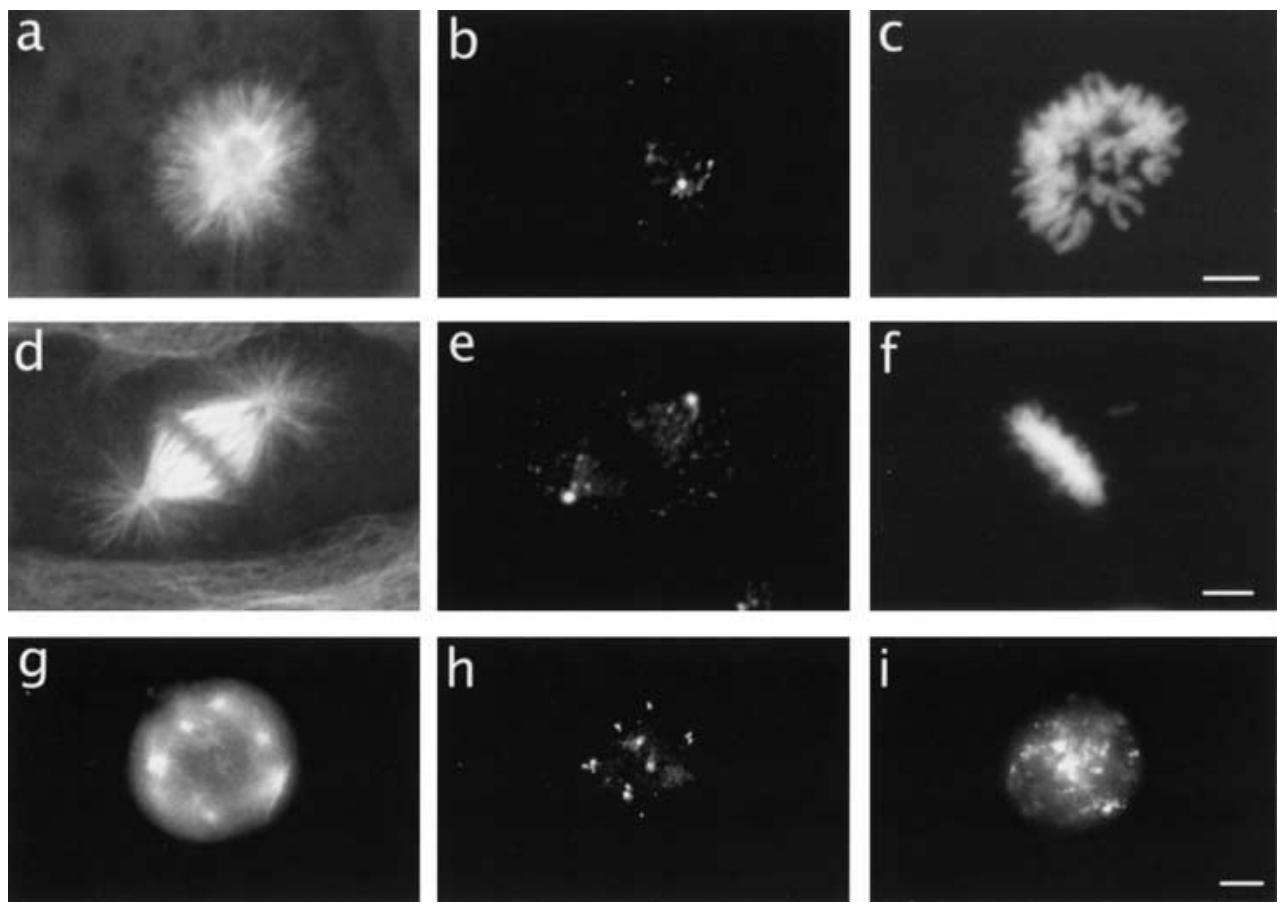

Figure 1. Monopolar, bipolar, and multipolar spindles. $(a-c)$ Monopolar spindle is assembled when the centrosomes fail to separate in a BSC-1 cell. This is a rare spontaneous occurrence in culture. Interestingly, BSC-1 cells, from which the centrosome has been removed during interphase, assemble bipolar spindles without centrosomes (Hinchcliffe et al. 2001), using the alternative spindle assembly pathway described in the text. The fact that cells with unseparated centrosomes form monopolar spindles indicates that centrosomes, when present, act in a dominant fashion to determine spindle polarity. ( $d-f)$ Example of a normal bipolar spindle in a BSC-1 cell. Note that one chromosome is monooriented in panel $f_{;}$a checkpoint pathway will hold the cell in mitosis until all chromosomes establish bipolar connections to the spindle. (g-i) Multipolar spindle in a Chinese hamster ovary (CHO) cell. This cell was arrested in S phase to allow the reduplication of the centrosome and then spontaneously entered mitosis. Note that the centrosomes are all well separated from each other, which would lead to several daughter cells with unequal numbers of chromosomes. The chromosomes appear abnormal because DNA synthesis was not complete. $(a, d, g)$ Microtubule distribution detected with a monoclonal anti- $\alpha$ tubulin antibody (Sigma). $(b, e, h) \gamma$ tubulin distribution detected by a polyclonal anti- $\gamma$ tubulin antibody (Sigma). (c, $f, i)$ DNA distribution detected with Hoechst 33258 staining. Fluorescence microscopy, images captured with a cooled CCD camera and C-imaging software (Compix Inc.). Bars in $c, f$, and $i$ represent $5 \mathrm{um}$.

p53 $3^{-/-}$mouse embryo fibroblasts at successive passages is consistent with this hypothesis (Chiba et al. 2000).

\section{The events of centrosome reproduction}

At the end of mitosis, each daughter cell inherits a single centrosome, and by the onset of the next mitosis, it contains just two centrosomes. This precise doubling of the interphase centrosome in preparation for mitosis is called centrosome duplication or reproduction. In higher animal cells, centrosome reproduction consists of four morphological events: (1) centriole splitting, (2) centriole duplication, (3) centrosome disjunction, and (4) daughter centrosome separation (Fig. 2).

Centriole splitting, or centriole disorientation, has been defined as the detachment and loss of orthogonal relationship between the mother-daughter centriole pair, observed during late $\mathrm{G}_{1}$ (Kuriyama and Borisy 1981; Wheatley 1982). Although this event has been commonly said to be the leading event in centrosome reproduction, the mother and daughter centrioles can widely separate from each other as early as telophase in some cultured cells (Mack and Rattner 1993; Piel et al. 2000, 2001). It is not known whether these separated centrioles are still joined by an extensible linkage or have truly split well before the $\mathrm{G}_{1}-\mathrm{S}$ transition.

Centriole duplication is first seen at the beginning of $S$ phase or during $\mathrm{S}$ phase by the appearance of short daughter centrioles, or procentrioles, at right angles to and separated slightly from the two original centrioles. These procentrioles elongate during $S$ and $G_{2}$, reaching mature length in mitosis or the following $G_{1}$ (Kuriyama and Borisy 1981; Lange et al. 2000).

The completion of centrosome reproduction occurs with centrosome disjunction at a variable time in $\mathrm{G}_{2}$, with pairs of mother-daughter centrioles going to each daughter centrosome (Aubin et al. 1980; Kochanski and Borisy 1990). The disjunction of the sister centrosomes is correlated with the activity of Nek2, the mammalian homolog of the Asperillus protein NIMA, a cell cycle regulatory kinase that contributes to driving the cell into mitosis (Fry et al. 1998; Mayor et al. 2000). In addition, 


\section{The Centrosome Duplication Cycle}
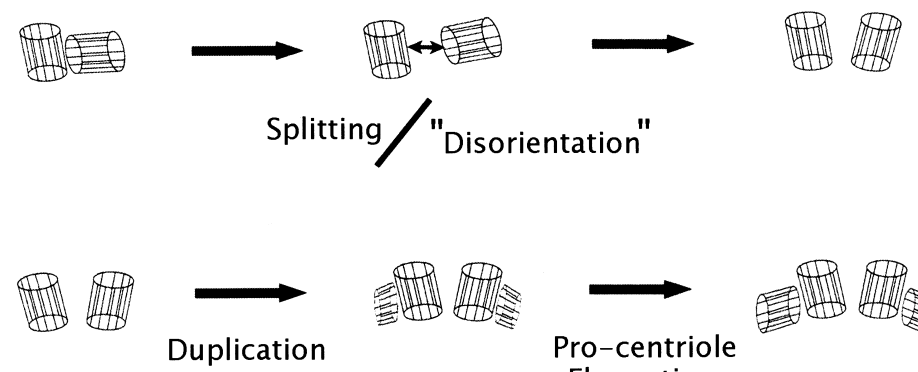

Pro-centriole Elongation

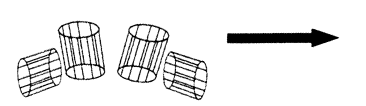

Disjunction
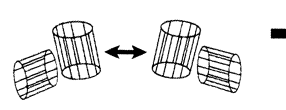

Separation
Figure 2. Schematic representation of the centrosome reproduction cycle; centrioles are represented as barrels, and the pericentriolar material is not shown. Centriole splitting/disorientation: During late $G_{1}$ or early $S$ phase, the mother and daughter centrioles separate slightly and lose their orthogonal orientation. Centriole duplication: Short, annular daughter centrioles, called procentrioles, are assembled at right angles to the parent centrioles. The procentrioles elongate during $S$ phase or $G_{2}$ and may not reach their full length until the following $G_{1}$. Centrosome disjunction: The duplicated centrosome disjoins during $\mathrm{G}_{2}$ into two functionally separate centrosomes, each containing a mother-daughter pair of centrioles. Centrosome separation: The sister centrosomes physically separate from each other through the action of microtubule-based motor proteins. phosphorylation of the EF-hand protein centrin during $\mathrm{G}_{2} /$ prophase correlates with centrosome disjunction (Lutz et al. 2001). The kinase activity of Nek2 and or the phosphorylation of centrin may function to coordinate sister centrosome disjunction with entry into mitosis, thereby ensuring that the cell contains two spindle poles at the right time.

This is followed by daughter centrosome separation through the action of microtubule-based motor proteins (Sharp and Scholey 2000). However, the extent to which aster separation occurs before the onset of mitosis can vary between cells, even those in the same population. In some cases, the two centrosomes remain close together until nuclear envelope breakdown, whereas in others, both asters are well separated around the nucleus before the end of prophase (for review, see Rieder 1990).

\section{Controls for centrosome reproduction}

Control of centrosome duplication is exercised by limits that are intrinsic to the centrosome itself and by extrinsic controls imposed by changing cytoplasmic conditions during cell cycle progression. Limits intrinsic to the centrosome determine the number of daughter centrosomes that arise from the parent centrosome; cytoplasmic controls determine when the centrosome duplicates in relation to the progression of nuclear events such as DNA synthesis and mitosis.

\section{Intrinsic controls}

Functional studies of living cells coupled with serial section electron microscopy indicate that there is a counting mechanism within each centrosome that limits the number of daughters that can arise from the parent centrosome. Zygotes contain enough centrosomal subunits at fertilization to assemble many complete centrosomes (Gard et al. 1990; Sluder et al. 1990), yet they normally assemble only one new centrosome in close spatial association with each preexisting centrosome at each cell cycle. This specificity of the duplication process appears to be determined by the cycle of centriole disjunction and centriole duplication. Because centrioles act to localize the PCM, as discussed earlier, the number of centriole pairs determines the number of spindle poles.

The evidence for this assertion originated with the remarkable finding of Mazia et al. (1960) that it is possible to experimentally manipulate the reproductive capacity of centrosomes in sea urchin zygotes. When mitosis is prolonged by any of several independent methods, the two spindle poles split during mitosis to yield four functional poles that will not further subdivide even when mitosis is prolonged to 20 times its normal duration (Mazia et al. 1960; Sluder and Begg 1985; Hinchcliffe et al. 1998). Ultrastructural analysis of such tetrapolar spindles reveals that each pole contains only one centriole, confirming that the centrosomes have split, not duplicated (Fig. 3; Sluder and Rieder 1985; Hinchcliffe et al. 1998). After the cell divides into four, these half centrosomes each assemble a daughter centriole, thus becoming normal centrosomes with full reproductive capacity. However, they do not undergo centriole splitting or centrosome disjunction, and each cell assembles a monopolar spindle at next mitosis (Fig. 4). In effect, the two mitotic centrosomes with normal reproductive capacity have subdivided into four centrosomes with half the normal reproductive capacity (and half the complement of centrioles). If a daughter cell with a monopolar spindle remains in mitosis longer than normal, as often happens, the centrosome of the monopolar spindle will split to 

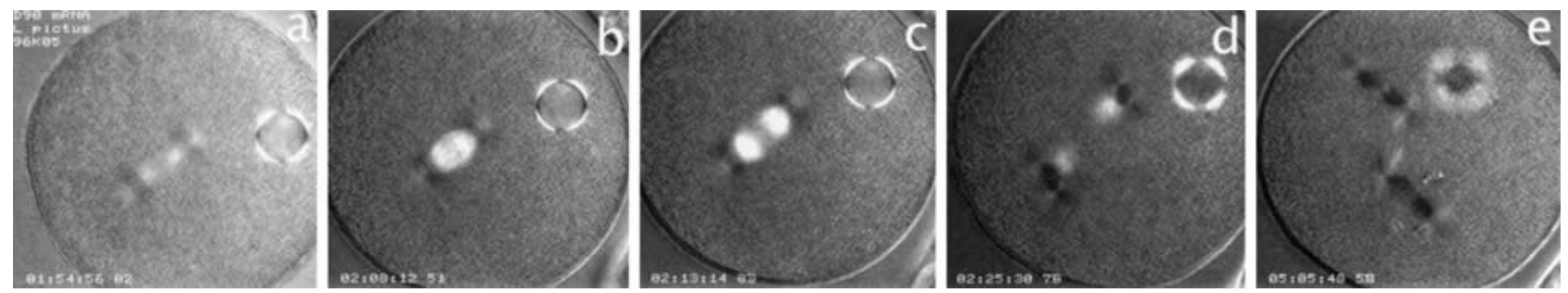

Figure 3. Sea urchin zygote arrested in first mitosis by the introduction of cyclin B $\Delta-90$ mRNA at first prophase. $(a, b)$ The zygote enters mitosis and assembles a normal bipolar spindle. The refractile sphere in the upper right portion of the zygote is a drop of oil used to cap the micropipet. (c) Anaphase onset occurs at the normal time. (d) The zygote remains in mitosis; both spindle poles have split and started to move apart. (e) Approximately $3 \mathrm{~h}$ after nuclear envelope breakdown, the split poles have moved further apart and two spindles are formed. Serial semithick section ultrastructural analysis of similar zygotes reveals that each spindle pole contains only one centriole. Thus, during mitosis mother-daughter centrioles can split apart and the centrosome can disjoin/separate yet the centrioles do not duplicate. polarization optics; 10 microns per scale division.

give two functional spindle poles with one centriole apiece. These poles undergo centriole duplication but not centrosome disjunction during interphase, and monopolar spindles are once again formed at the following mitosis. These observations reveal that each centriole can organize a functional spindle pole, but normally the mother and daughter centrioles remain physically associated with each other, thereby forming only one spindle pole. The importance of centrioles in the control of centrosome number was further substantiated by the finding that sea urchin zygotes, from which the centrioles were removed, would form a single MTOC. This MTOC would not double between mitoses (Sluder et al. 1989). Thus, the mechanism that determines the doubling of a spindle pole in preparation for mitosis is not part of the
PCM. Although all of this work was performed on sea urchin zygotes, these observations are not peculiar to embryonic cells. When mitosis is prolonged in cultured cells by transfection with a nondegradable cyclin B construct, the spindle poles double from two to four (Gallant and Nigg 1992).

The link between the cycle of centriole duplication and spindle pole reproduction, however, begs the question of how cells without centrioles manage to organize bipolar spindles during successive mitoses. Presumably, such cells use the alternate spindle assembly pathway, described earlier, by which microtubules nucleated in the vicinity of chromatin are sorted by microtubulebased motor proteins and then bundled in a bipolar array by crosslinkers such as NuMa (for review, see Compton

A.

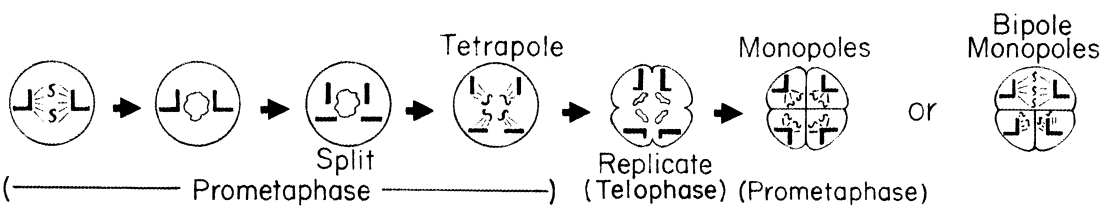

B.

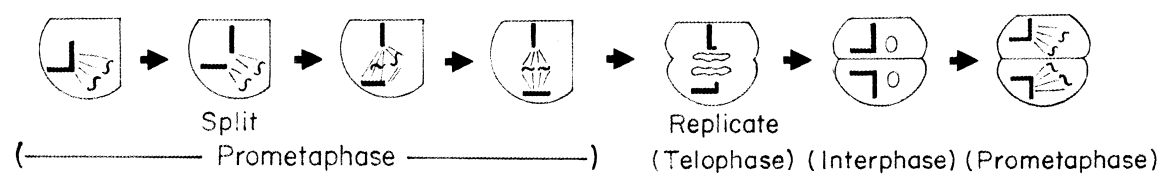

Figure 4. Diagrammatic representation of the experimental manipulation of the reproductive capacity of spindle poles in zygotes. (a) The first division spindle has a pair of orthogonally arranged centrioles at each spindle pole. During prolonged prometaphase, the centriole pairs (and centrosomes) split without duplicating, and the four spindle poles separate from each other, each containing a single centriole. In telophase, as the cell divides into four, the singlet centrioles replicate but do not separate. The result is the formation of monopolar spindles at the next mitosis. Each centrosome has the normal complement of two centrioles. When a cleavage furrow fails to form, two monopolar spindles come together to assemble a functional bipolar spindle with poles that reproduce in a normal fashion. $(b)$ Centriole behavior during prolonged prometaphase in a cell containing a monopolar spindle. The single pole splits and a bipolar spindle forms when prometaphase is prolonged, as it often is in such cells. Each sister aster contains only one centriole. After anaphase, the cell divides and the singlet centrioles duplicate but do not split during interphase. At the next mitosis, monopolar spindles are again assembled. 
2000). This means that spindle pole duplication does not exist in acentriolar cells; the poles of the spindle are formed anew at each mitosis.

The mechanism for the precise one-to-two duplication of centrioles is not understood. Our current thinking is that centriole replication is a templated process whereby the parent centriole provides a unique site and/or pattern for the assembly of the daughter centriole. Specific precursor structures, such as an annular ring or a looped fiber containing 9 densely staining foci that later elaborate into triplet microtubules, have been described in ciliate basal body duplication (Dippel 1968; Gould 1975). This templating hypothesis is supported by findings that zygotes have sufficient complete pools of centrosome subunits to make many centrosomes, yet daughter centrosomes form only one at a time at the parent centrosome (Gard et al. 1990; Sluder et al. 1990). Also, when the centrosome is removed from zygotes (Sluder et al. 1989) or somatic cells (Maniotis and Schliwa 1991; Hinchcliffe et al. 2001; Khodjakov and Rieder 2001), centrioles do not reassemble. To the best of our knowledge, the only exceptions to this rule are found in the de novo formation of centrioles after parthenogenetic activation of sea urchin eggs (Von Ledebur-Villiger 1972; Kallenbach and Mazia 1982), the formation of multiple basal bodies from specialized generative structures during spermiogenesis in the water fern Marselia (Hepler 1976), and the assembly of multiple basal bodies from specialized generative structures in ciliated epithelia in higher animals (Sorokin 1968; Dirksen 1991). In addition, centriole/basal body genesis can be under developmental control. For example acentriolar Naeglaria amoebae will assemble two basal bodies when they differentiate into a flagellated form after environmental stress (Fulton and Dingle 1971). In addition, during mouse development, centrioles are not seen in the early mitotic divisions (Szollosi et al. 1972).

Historically, the implied continuity of structure and pattern in centriole duplication has brought to mind DNA replication, the contemporary paradigm for a templated reproductive process in which information and copy number are under rigid control. Thus, it is not surprising that almost 40 years ago, workers started considering the notion that centrioles and basal bodies contain nucleic acids that serve either a genomic or structural role in the duplication process. The thinking was that centrioles could be semiautonomous organelles with their own DNA genomes, much like mitochondria and chloroplasts. Alternatively, centrioles, like ribosomes, could contain RNA that would serve a structural role in the assembly of daughter centrioles. These possibilities inspired searches, spanning many years, for nucleic acids physically located in centrioles and basal bodies. The vast majority of these studies concentrated on trying to show the existence of DNA or RNA in centrioles/basal bodies under the assumption that presence implies function; only a few studies were designed to test the functional importance of nucleic acids in centrosome activity. Over the years, claims that DNA or RNA is the sole centriolar nucleic acid, have alternately achieved favor.
Because all of this work was fraught with serious technical problems and with initially promising but ultimately inconclusive observations, we will not review this field. The early work was reviewed by Fulton (1971), and the later work has been reviewed by Marshall and Rosenbaum (2000). Suffice it to say, there is yet no credible evidence for the existence of DNA in centrioles or basal bodies, and claims to this effect have been discredited by the most recent experimentation. Although RNA may be present at or in the vicinity of centrioles, there is no compeling evidence for its importance in centriole duplication or centrosome assembly/function. Understandably, nobody has been able to rigorously differentiate between RNAs that are specific to the centriole and nuclear gene products, such as ribosomal, transfer, or messenger RNAs, which happen to lie within the cytoplasmic volume of the centriole or basal body. Thus, it appears that this seductive siren song about the role of nucleic acids in the control of centrosome duplication and function has been marginalized-for now.

\section{Extrinsic controls}

The cell must ensure that the events of centrosome reproduction are properly coordinated with nuclear events in the cell cycle if it is to have just two centrosomes at the onset of mitosis. Although much progress has been made over the past 15 years in defining the controls that ensure this essential coordination, we still do not have enough pieces of the puzzle to provide a complete picture. Because this field has progressed largely by testing a variety of hypothetical control strategies, we will review the potpourri of studies by category. By beating around the bush long enough, we hope to eventually define the outlines of the bush.

\section{The time of centrosome reproduction is under cytoplasmic control}

In principle, a logical way for the cell to coordinate nuclear and centrosomal events would be for nuclear activities, such as the synthesis of DNA and/or the timed transcription of RNAs, to determine when the centrosome can reproduce. This possibility was tested by using a micropipette to remove the nucleus and one centrosome from sea urchin zygotes (Sluder et al. 1986). These zygotes were ideal for this investigation because they contain large stores of mRNAs and proteins to support rapid early development without growth, and consequently, the cell cycle continues in the absence of the nucleus. The results of these experiments revealed that remaining centrosome invariably reproduced in a one-totwo-to-four-to-eight fashion in proper coordination with cycles of astral microtubule assembly/disassembly and cleavage furrow initiation. The fact that all daughter centrosomes contained two centrioles indicated that centrosome reproduction was normal and complete. Thus, neither the presence of the nucleus nor its activities are required for repeated cycles of centrosome repro- 
duction; temporal control of centrosome reproduction is under cytoplasmic control. The finding that all the centrosomes reproduced in synchrony within a zygote indicates that the temporal control of their reproduction is exercised by a cyclical change in the state of the cytoplasm.

\section{Cell cycle stage and centrosome duplication}

The way in which the centrosome and nuclear cycles are coordinated might seem to be straightforward at first glance: The events of centrosome reproduction could be driven by cytoplasmic conditions particular to certain cell cycle stages. However, the appealing simplicity of this notion was clouded by demonstrations that centrosomes repeatedly reproduce when the cell cycle is arrested in interphase by inhibitors of DNA synthesis or protein synthesis (Sluder and Lewis 1987; Raff and Glover 1988; Gard et al. 1990; Sluder et al. 1990; Balczon et al. 1995). Such findings raised the possibility that the nuclear and centrosomal cycles are regulated by independent pathways (Sluder et al. 1990). Thus, it was important to experimentally define which cell cycle stages support centrosome reproduction and which do not. The approach used has been to arrest cells at various phases of the cell cycle and then to determine whether the centrosome will reproduce one or more times without further experimental intervention.

$G_{O}$ phase: This phase of the cell cycle does not support centrosome reproduction. The centrosome does not duplicate as long as the cell is in this quiescent phase of the cell cycle (Tucker et al. 1979; Okuda et al. 2000).

$G_{1}$ phase: Whether or not centrosome reproduction begins during $G_{1}$, when the cell has passed the restriction point and is committed to prepare for division, appears to vary among different cell systems. In the vast majority of cell types examined, the start of centrosome reproduction, as seen by procentriole formation, does not occur until the very end of $\mathrm{G}_{1}$ or during $\mathrm{S}$ phase (Robbins et al. 1968; Kuriyama and Borisy 1981; Vorobjev and Chentsov 1982; Alvey 1985; for review, see Hinchcliffe and Sluder 1998). Also, when the cell cycle is arrested in $\mathrm{G}_{1}$ with mimosine, the centrosome does not appear to double, as seen by the number of gamma tubulin immunoreactive spots (Matsumoto et al. 1999). However, the temporal correlation between procentriole formation and onset of $\mathrm{S}$ phase is not universal. For example, high proportions of L929 cells in culture form procentrioles $4 \mathrm{~h}$ before the onset of DNA synthesis (Rattner and Phillips 1973). In addition, $\mathrm{p} 53^{-/-}$mouse embryonic fibroblasts (MEFs) released from serum starvation can assemble multiple centrosomes well before the onset of $S$ phase (Fukasawa et al. 1996). Finally, in sea urchin zygotes arrested in interphase before the onset of DNA synthesis of the second cell cycle, the centrosome inherited by each blastomere reproduces completely, but just once (Hinchcliffe et al. 1998). Together, these observations indicate that the $G_{1}$ phase of the cell cycle can support the morphological aspects of centrosome reproduction, such as the assembly of daughter centrioles and the splitting/separation of the duplicated centrosomes.

Although the reason why some cells will initiate (and even complete) centriole duplication during $G_{1}$ and others wait until the onset of $S$ phase is not understood; this variability may be rooted in system-dependent differences when cyclin-dependent kinase 2-cyclin E (Cdk2-E) activity rises (Cdk activity in the control of centrosome duplication is discussed below). Also, it is possible that the early steps of centriole duplication, such as the formation of precursor structures, occur well before DNA synthesis begins. Procentriole formation first seen at the onset of $S$ phase could be the physical manifestation of the initial reproductive processes that began in $\mathrm{G}_{1}$ or, conceivably, in the previous cell cycle. This issue is important because any effort to experimentally identify cell cycle regulatory pathways that control centrosome duplication will be facilitated by an understanding of when the reproductive processes actually begin.

$S$ phase: The cytoplasmic conditions of $S$ phase are clearly permissive for the complete cycle of centrosome reproduction, including mother-daughter centriole splitting, duplication, and centrosome disjunction/separation. Prolongation of $\mathrm{S}$ phase in both zygotes and Chinese hamster ovary ( $\mathrm{CHO}$ ) somatic cells allows multiple rounds of centrosome duplication to occur without cell cycle progression (Fig. 5; Sluder and Lewis 1987; Raff and Glover 1988; Balczon et al. 1995; Hinchcliffe et al. 1998; Winey 1999). Whether this phenomenon is peculiar to zygotes and certain somatic cell lines or alternatively is a general phenomenon is an important question that has yet to be thoroughly investigated. If this is a general phenomenon, one can ask why centrosomes normally do not reduplicate during $S$ phase, especially when DNA synthesis is slowed by environmental perturbations. A possible answer comes from the finding that the period of centrosome reduplication during $S$ phase arrest is on average more than twice as long as the entire cell cycle in sea urchin zygotes and CHO cells (Balczon et al. 1995; Hinchcliffe et al. 1998). Under normal circumstances, therefore, $\mathrm{S}$ phase does not last long enough for centrosomes to reduplicate.

We note that under normal circumstances, the duplicating or duplicated centrosome does not split and separate into two daughters during $G_{1}$ or $S$ phases; this event occurs during $G_{2}$ or, in some cases, at the onset of $M$. We do not yet know if this reflects independent regulation of duplication and disjunction/separation or rather the relatively slow kinetics of the separation event after the centrosome has duplicated. However, the observations of Fry and Nigg (1998) indicate that a rise in Nek2 kinase activity during $\mathrm{G}_{2}$ is required to phosphorylate a protein called cNAP, which in turn is thought to provide the physical link between daughter centrosomes (Mayor et al. 2000). Observations that the complete cycle of centrosome duplication/separation can occur during prolonged S are consistent with the possibility that the separation of daughter centrosomes begins as soon as the 

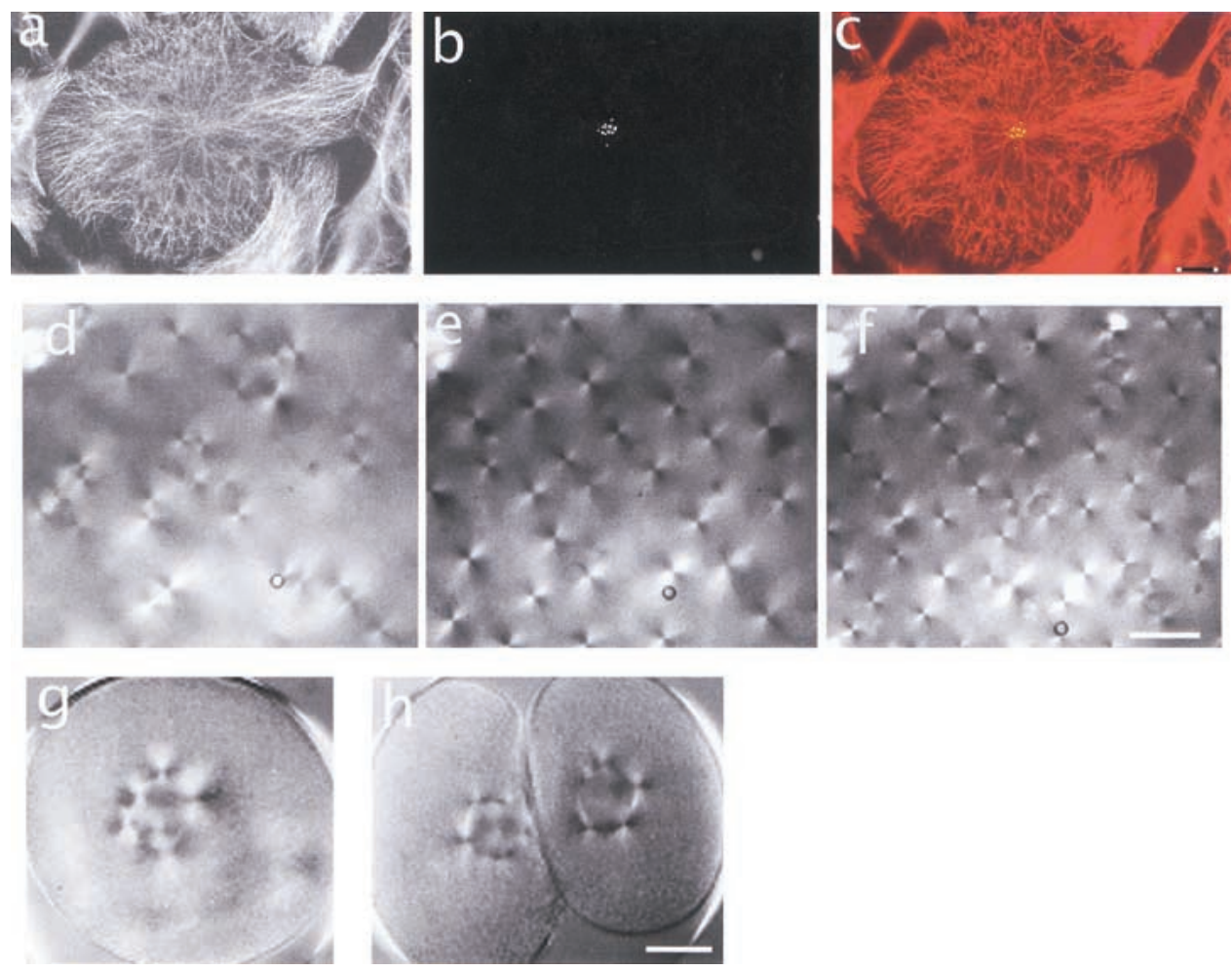

Figure 5. Reduplication of the centrosome during prolonged S phase: three experimental systems. (a) Chinese hamster ovary (CHO) cell arrested in $\mathrm{S}$ phase for $60 \mathrm{~h}$ by aphidicolin; tubulin distribution. $(b) \gamma$ tubulin distribution reveals a number of centrosomes clustered adjacent to the nucleus. (c) Merged tubulin and gamma tubulin distributions. (d-ITLf) Multiple rounds of centrosome duplication in a $\mathrm{S}$ phase arrested Xenopus egg extract. Centrosome duplication is seen here by the doubling of the number of microtubule asters. $(g, h)$ Centrosome reduplication in sea urchin zygotes arrested in first $\mathrm{S}$ phase and second S phase. $(a-c)$ Fluorescence microscopy. $10 \mu \mathrm{m}$ per scale division. $(d-h)$ Polarization microscopy. Bars $=10 \mu \mathrm{m}$.

parent centrioles split apart, but occurs slowly. In this regard, it will be of great interest to determine the activity of Nek2 during prolonged S phase.

$G_{2}$ phase: Although the daughter centrosomes normally disjoin and separate during $\mathrm{G}_{2}$, this phase of the cell cycle does not appear to support continued centrosome duplication. $\mathrm{CHO}$ cells arrested in $\mathrm{G}_{2}$ with the topoisomerase inhibitor etoposide contain only two sister centrosomes, whereas the same cells arrested in $S$ assemble multiple centrosomes (Balczon et al. 1995).

M phase: The cytoplasmic conditions of mitosis do not support centrosome reproduction but do allow motherdaughter centriole splitting and separation. As mentioned above, sea urchin zygotes microinjected with mRNA coding for cyclin B $\Delta 90$ arrest in M phase for up to 20 times the normal duration (Hinchcliffe et al. 1998). The two centrioles at each spindle pole split but do not duplicate (Fig. 3; Gallant and Nigg 1992). In addition, recent work has shown that centrosome duplication does not occur in Drosophila embryos (Vidwans et al. 1999) or Xenopus egg extracts (Lacey et al. 1999) that are arrested in mitosis.

Together, these findings indicate that the temporal control of the events of centrosome reproduction is exercised by the cytoplasmic conditions of specific cell cycle stages. The correlation between cell cycle stage and the ability of the centrosome to reproduce has therefore directed attention to the role of cell cycle regulatory kinases in centrosome duplication. Logically, the sequential activation of the Cdks could coordinately drive centrosome duplication and nuclear events in the cell cycle.

\section{Cdks in the control of centrosome duplication}

\section{Mitotic Cdks}

Back when the picture of cell cycle regulation was simple, it was of interest to determine whether centrosome reproduction was controlled by Cdk1-cyclin B, the kinase complex that participates in driving the cell into mitosis. The demonstration that centrosomes repeatedly reproduce when progression of the cell cycle is blocked in interphase by complete inhibition of protein synthesis (Gard et al. 1990; Sluder et al. 1990) revealed that centrosome duplication cannot be driven in any simple way by the cyclic rise and fall of Cdk1-cyclin A or Cdk1-B activity, which depend on the synthesis of these cyclins during each cell cycle. Further investigation of this issue has also established that the absolute value of Cdk1-B activity, be it high or low, does not establish cytoplasmic 
conditions that favor or inhibit centrosome reproduction (Hinchcliffe et al. 1998).

\section{Cdks of the $G_{1}$-S transition}

A number of recent studies have revealed that Cdk2 activity plays a key role in controlling centrosome reproduction in both early zygotes and somatic cells. These investigations were motivated by the knowledge that the activation of Cdk2-cyclin E and Cdk2-cyclin A is required for the $G_{1} / S$ transition and the maintenance of $S$ phase progression (Strausfeld et al. 1996), times in the cell cycle when mother-daughter centrioles split apart and start to assemble procentrioles. To test the role of Cdk2-E in the duplication of centrosomes, the activity of this kinase was specifically inhibited in a Xenopus egg extract-arrested in $S$ phase-that supports multiple rounds of centrosome duplication in vitro (Hinchcliffe et al. 1999). When $\Delta 34$ Xic- 1 was added to the extracts, multiple rounds of centrosome duplication were blocked. This $\mathrm{NH}_{3}$-terminal truncated variant of the Xenopus Cdk inhibitor Xic- $1^{\mathrm{p} 27}$ inhibits Cdk2-E activity but not Cdk1-cyclin A or Cdk1-cyclin B at the concentration used (Su et al. 1995; Hartley et al. 1997). When an excess of purified Cdk2-E was added to the $\Delta 34$ Xic-1-treated extracts, multiple rounds of aster duplication were restored. Cdk2-cyclin A activity was not a factor in these experiments, because Cdk2 does not complex with cyclin A until after the mid blastula transition in Xenopus (Rempel et al. 1995; Hartley et al. 1997). Because the majority of $S$ phase promoting activity is provided by Cdk1-A activity (Strausfeld et al. 1996), which is not inhibited by $\Delta 34$ Xic- 1 at the concentrations used, the inhibition of Cdk2-E should not drive the cell cycle out of S phase.

In addition, Lacey et al. (1999) arrested Xenopus embryos in interphase with protein synthesis inhibitors to allow repeated centrosome duplication without cell cycle progression (Gard et al. 1990). When individual blastomeres were microinjected with the Cdk inhibitors p21 or p27 to inhibit the activity of Cdk2-E (Elledge and Harper 1994; Jackson et al. 1995), the centrosomes in the injected cells did not repeatedly duplicate as did those in the uninjected cells of the same zygote. In addition, these workers used egg extracts containing centrosomes isolated from cultured cells to show that Cdk2-E activity is required to promote mother-daughter centriole splitting, thought to be the earliest event in the centrosome duplication cycle.

The role of Cdk2 in regulating centrosome duplication is not peculiar to embryonic cells; repeated centrosome duplication in S phase-arrested $\mathrm{CHO}$ cells depends on Cdk2 activity (Matsumoto et al. 1999). However, in somatic cells it appears that Cdk2 coupled with cyclin A is more effective than $\mathrm{Cdk} 2$-E in restoring multiple rounds of centrosome duplication in $\mathrm{CHO}$ cells arrested at the $\mathrm{G}_{1} / \mathrm{S}$ transition by transfection with a mutant form of $\mathrm{Rb}$ that lacks Cdk phosphorylation sites (Meraldi et al. 1999). Whereas coexpression of cyclin A restored significant levels of repeated centrosome duplication, over-ex- pression of cyclin E did not. Their finding that cotransfection with a dominant-negative Cdk2 construct did not restore centrosome duplication indicated that the cyclin A effect was not an artifact but rather was caused by an increase in Cdk2-A activity. In addition, these findings indicate that the action of Cdk2-A in centrosome duplication occurs downstream from its role in the $\mathrm{Rb}$ phosphorylation pathway needed to drive the $\mathrm{G}_{1} / \mathrm{S}$ transition. Although these observations raise the interesting possibility that somatic cells and early cleavage stage zygotes use different Cdk2-cyclin complexes to regulate centrosome reproduction, this may not reflect fundamentally different control strategies. Perhaps centrosomes are responsive to both Cdk2-A and Cdk2-E. Because Cdk2 does not complex with cyclin A until the mid blastula transition in Xenopus zygotes, Cdk2-E may be the only kinase complex available. In somatic cells that contain both Cdk2-A and Cdk2-E kinase complexes, Cdk2-A activity may also play an important role in promoting centrosome duplication. Regardless of these possible differences in the regulation of centrosome duplication between various cell types, cell cycle progression into $S$ phase and centrosome duplication appear to be linked through a rise in Cdk2 activity.

\section{Nucleophosmin NO38/B23, the target of Cdk2-E finase activity}

The next important step was to identify the substrates for Cdk2 that are involved in the control of centrosome duplication. In principle, Cdk2 complexed with cyclins E or A could act directly to phosphorylate proteins of the centrosome or activate a pathway that in turn acts on the centrosome. A recent report by Okuda et al. (2000) has provided important insight into the centrosomal target for Cdk2. Their approach was deceptively simple: Unreplicated centrosomes were isolated from $G_{0}$ Swiss 3T3 cells and incubated with purified Cdk2-cyclin $\mathrm{E}$ and p32-ATP in vitro. Remarkably, only a single major polypeptide was phosphorylated beyond those phosphorylated in the control preparations lacking centrosomes. This polypeptide was isolated by 2D gel electrophoresis, excised from the gels, and trypsenized, and the resultant peptides were analyzed by MALDI-TOF mass-spectroscopy. This polypeptide turned out to be nucleophosmin NO38/B23, a previously identified component of the nucleous implicated in, among other things, ribosome assembly (Schmidt-Zackman et al. 1987). Consistent with this finding, nucleophosmin NO38/B23 had previously been shown to localize to mitotic spindle poles in HeLa cells (Zatsepina et al. 1999) and is thought to be phosphorylated by Cdk1-B during mitosis (Peter et al. 1990).

Immunofluorescence analysis of Swiss 3T3 cells revealed that nucleophosmin NO38/B23 localizes to unduplicated centrosomes but is not found on centrosomes after duplication. Later, when the cells are in mitosis, nucleophosmin is again observed at the centrosomes. Importantly, they found that microinjection of antibodies to rat nucleophosmin NO38/B23 blocked the duplication of centrosomes. In addition, expression of a 
mutant of nucleophosmin NO38/B23 that is nonphosphorylatable by Cdk2-E also blocked centrosome reproduction. Random thin-section electron microscopy of cells expressing the nonphosphorylatable form of nucleophosmin NO38/B23 indicated that the centrioles had not split apart.

Together, these results indicate that nucleophosmin NO38/B23 associates with centrosome during mitosis, thereby preventing their splitting and duplication until late $G_{1}$, when Cdk2-E activity rises in preparation for $S$ phase. Cdk2-E-specific phosphorylation of nucleophosmin causes it to come off of the centrosome, thereby allowing centriole disorientation and splitting to occur. This is followed by the assembly of procentrioles and hence reproduction of the centrosome. Going forward, it will be interesting to investigate why centrioles can split apart during prolonged mitosis (Sluder and Begg 1985; Gallant and Nigg 1992), a point in the cell cycle when nucleophosmin should be associated with the centrosome. Perhaps the Cdk2-E-mediated phosphorylation of nulceophosmin does not influence the splitting of the mother-daughter centrioles but rather limits the assembly of daughter centrioles. Also, it will be of interest to determine if Cdk2-cyclin A also phosphorylates nucleophosmin NO38/B23 at sites that cause it to dissociate from the centrosome, as would be predicted by the results of Meraldi et al. (1999).

\section{Ubiquitin-mediated proteolysis and the centrosome cycle}

Recently, a number of laboratories have investigated whether proteolysis of centrosomal components or proteins that interact with the centrosome are needed for centrosome duplication. Interest in this stems from findings that ubiquitin-mediated proteolysis of regulatory proteins, such as certain cyclins, proteins involved in chromatid cohesion, and Cdk inhibitors, is of fundamental importance for the execution of a number of transition points in the cell cycle (King et al. 1996). Perhaps the proteolysis of putative centrosome-associated proteins determines if and when the centrosome will duplicate. An important issue in this sort of investigation is the need to differentiate between the proteolysis of cell cycle regulatory proteins needed for the cell cycle to progress to the point that the centrosome is scheduled to duplicate and the proteolysis of proteins that interact with the centrosome to limit its duplication.

Specific proteins are targeted for degradation by the covalent attachment of a chain of ubiquitin proteins by multicomponent ubiquitin ligase complexes or E3 complexes (for review, see Jackson et al. 2000). Such ubiqutinated proteins are recognized by the $26 \mathrm{~S}$ proteosome and are completely degraded while the ubiquitin is recycled. Because the proteosome will degrade any poly-ubiquitinated protein, the various E3 complexes have the substrate specificity that determines which particular proteins are targeted for proteolysis at any given time (Jackson et al. 2000). Two E3 complexes have been implicated in the regulation of centrosome reproduction: the SCF complex, which contains Skp1, Cdc53/Cul1 and one of several F-box proteins (for review, see Winston et al. 1999) and the anaphase promoting complex or cyclosome $(\mathrm{APC} / \mathrm{C}$; for review, see Zachariae and Nasmyth 1999).

The first indications that E3-mediated proteolysis could play a role in the control of centrosome duplication came from genetic studies on budding yeast. The SCF components Cdc4 (an F-box protein) and Cdc53 (a cullin), as well as Cdc34 (an ubiquitin-conjugating enzyme or E2), are required not only for entry into $S$ phase but also for the separation of duplicated spindle pole bodies (SPBs), the yeast centrosome equivalent (Mathias et al. 1996). In addition, Pcs1, which encodes a subunit of the proteosome cap, was also found to be required for duplication of the SPB (McDonnell and Byers 1997). In human cells Cdc16hs and Cdc27hs (components of the APC/C), Skp1 and the 26S proteosome have been localized to centrosomes during interphase and mitosis (Tugendreich et al. 1995; Gstaiger et al. 1999; Wigley et al. 1999).

\section{Proteolysis regulating centrosome duplication: A split decision?}

To directly test whether SCF-mediated proteolysis is involved in initiating centrosome reproduction, Freed et al. (1999) inhibited SCF activity in a Xenopus egg extract that supports the splitting of mother-daughter centrioles (Lacey et al. 1999). They found that inactivating antibodies to either Skp1 or Cul1 greatly diminished the percentage of mother-daughter centriole pairs that split apart. Because SCF-mediated degradation of p27 is required for the activation of Cdk2-E (Lacey et al. 1999; Winston et al. 1999), they added purified Cdk2-cyclin E to the antibody-treated extracts. The finding that this did not restore centriole splitting led them to conclude that SCF-mediated proteolysis controls the initial events of centrosome reproduction directly through the destruction of centrosomal component(s). This conclusion was bolstered by their finding that inhibition of the $26 \mathrm{~S}$ proteosome with high concentrations of clasto-lactacystin $\beta$-lactone (CLBL; Fenteany and Schreiber 1998) also blocked the splitting of the mother-daughter centriole pairs in egg extracts. This phenomenon is not peculiar to egg extracts because CLBL blocked the reduplication of centrosomes in early Xenopus embryos that were treated with cyclohexamide.

Although these findings indicate that proteolysis is involved in centrosome duplication, the story has been complicated by evidence indicating that SCF-mediated proteolysis is required to prevent the centrosome from undergoing multiple rounds of duplication during a single cell cycle. First, Nakayama et al. (2000) produced a mouse knockout for Skp2, an F-box protein involved in targeting the degradation of-amongst other proteinsthe Cdk inhibitor p2 $7^{\mathrm{kip} 1}$ (Carrano et al. 1999). The fact that Skp2 $2^{-/}$mice exist and are viable up to at least 10 months indicates that centrosome function and duplication are sufficiently normal to support development and 
adult body function. Of interest, however, was their finding that $38 \%$ of $\mathrm{Skp} 2^{-1-}$ mouse embryonic fibroblasts (MEFs) showed three to 12 centrosomes per cell as determined by the number of pericentrin-containing bodies. Although this result indicates, at face value, that the centrosome undergoes repeated rounds of duplication without $\mathrm{SCF}^{\mathrm{skp} 2}$-mediated proteolysis, plieotropic effects cannot be ruled out. Many Skp2 $2^{-/-}$cells contained micronuclei, which is suggestive of problems with spindle assembly and/or function. Also, the levels of both cyclin $\mathrm{E}$ and $\mathrm{p} 27^{\mathrm{kip} 1}$ were increased in Skp2-/MEFs without a commensurate increase in Cdk2-E activity compared with the Skp2 $2^{+/+}$and Skp2 $2^{+/-}$cells. This is not surprising given the role of Skp2 in targeting $\mathrm{p} 27^{\mathrm{kip} 1}$ for degradation, thereby allowing Cdk2-E to become active. These investigators suggest that the repeated duplication of centrosomes in Skp2 $2^{-/-}$MEFs is because of the overexpression of cyclin E. However, the way in which the overexpression of cyclin E without an increase in its activity could lead to the formation of multiple centrosomes is not clear, because the constitutive expression of cyclin $\mathrm{E}$ in both immortalized rat embryonic fibroblasts and human breast epithelial cells does not lead to multiple centrosomes, as judged by the number of $\gamma$ tubulin immunoreactive foci per cell (Spruck et al. 1999).

Second, Wojcik et al. (2000) report that $66 \%$ of the neuroblasts of centrosome replication-defective (crd) Drosophila embryos contained three to 17 centrosomes per cell. The crd mutation was found to be an allele of supernumerary limbs (slimb), a previously identified Fbox protein (Jiang and Struhl 1998). This study does not reveal the identity of any proteins targeted for degradation by the slimb containing SCF complex, but the investigators speculate that one possible target could be cyclin E.

\section{Different F-boxes, different functions?}

Taken together, these studies raise the question of whether proteolysis is required to initiate centrosome splitting and subsequently reproduction, as suggested by Freed et al. (1999), or alternatively whether proteolysis functions to limit centrosome reproduction to once per cell cycle, as suggested by the results of Nakanyama et al. (2000) and Wojik et al. (2000). The answer may be both. Perhaps Skp1- or Cull-containing SCF complexes are needed to target certain centrosomal proteins for degradation, thereby allowing duplication, whereas Skp2 and/or slimb-containing SCF complexes are required to degrade other proteins after duplication to prevent reduplication of the daughter centrosomes. In this regard, it will be interesting to determine the behavior of centrosomes in cells from mice lacking either Cul 1 (Wang et al. 1999) or Cul 3 (Singer et al. 1999), both of which lead to high levels of cyclin E protein.

\section{APC/C activity and centrosome reproduction}

The APC/C is an E3 complex that plays a key role in the metaphase-anaphase transition by poly-ubiquitinating cyclin B and proteins involved in chromatid cohesion, thereby targeting them for proteolytic degradation. Whether or not APC-mediated proteolysis of centrosomal proteins at the end of mitosis is required for centrosome duplication at the following $G_{1}-S$ transition has not been thoroughly investigated. However, preliminary indications indicate that proteolysis at this point in the cell cycle does not determine when centrosomes will reproduce. First, sea urchin zygotes expressing a nondegradable form of cyclin B (cyclin B $\Delta 90$; Murray et al. 1989) arrest in mitosis because Cdk1-cyclin B activity remained high (Hinchcliffe et al. 1998). Nevertheless, the proteolytic events of the metaphase-anaphase transition occur because the cells initiate anaphase chromosome movement and endogenous cyclin B is degraded (Glotzer et al. 1991; Holloway et al. 1992). At or shortly after anaphase onset, the spindle poles split but do not duplicate. The fact that the centrosomes did not fully reproduce indicates that proteolysis at the metaphase transition is not the sole limit to centrosome reproduction while the cell is in mitosis. However, we do not know if such proteolysis is necessary to prepare centrosomes for duplication at the following $G_{1}-S$ transition. We note that even though the splitting of the mitotic centrosomes is temporally correlated with anaphase onset, this does not imply a role for APC-mediated proteolysis in the splitting of mother-daughter centrioles. Mitosis is often prolonged in zygotes containing a monopolar spindle; under such conditions the centrosome splits, and the cell assembles a bipolar spindle that only later initiates anaphase (Sluder and Begg 1985). This means that the splitting of the mother-daughter centrioles and the disjunction of the centrosome as a whole can occur without the proteolytic events of the metaphase-anaphase transition.

\section{Future directions}

Despite the significant advances that have been recently made in unraveling the web of control mechanisms both intrinsic and extrinsic to the centrosome, it is becoming evident that the controls for centrosome duplication are more complex than we expected. Perhaps this is not surprising, because centrosome duplication involves the highly regulated assembly of complex, multifunctional organelles such as the centrioles and the PCM, which in turn must interface with the pathways that regulate the cell cycle. Although we have found a number of pieces to this puzzle, we do not yet have enough of them to provide a coherent picture.

Looking forward, there are a number of fascinating issues to explore and existing leads that need further work. For example, does centrosome duplication require a microtubule network to transport subunit proteins to the cell center (Balczon et al. 1999; Purohit et al. 1999), and to what extent does this limit centrosome duplication and function. Also, how do the activities of the polo kinases (for review, see Glover et al. 1999) and the Aurora kinases (for review, see Giet and Prigent 1999; Goepfert and Brinkley 2000) play a direct role in control- 
ing the events of centrosome reproduction, and how do they effect the physical separation of duplicated centrosomes through their regulation of the activity of microtubule-based motor molecules. These are particularly important issues because human Aurora 2 kinase (also known as STK15 and BTAK) is overexpressed in many human tumor cell types, including breast and colon tumors, that show centrosome amplification (Zhou et al. 1998). Indeed, ectopic expression of STK15 in mouse NIH 3T3 cells leads to the appearance of abnormal centrosome number (amplification) and transformation in vitro (Zhou et al. 1998). Although the emerging complexity of the control mechanisms involved in centrosome duplication-particularly as it relates to aneuploidy and tumorgenesis-means that there is more work ahead, we should be pleased that our dance with the centrosome will continue.

\section{Acknowledgments}

We would like to thank Alexey Khodjakov, Jim Maller, Bob Palazzo, and Conly Rieder for discussions on centrosomes and cell cycle control. We would also like to acknowledge the assistance of Rick Miller for his substantial contributions to many of the studies reviewed here. This work supported by a grant to GS from the NIH (GM 30758). E.H.H. is supported by a senior postdoctoral fellowship from the American Cancer Society, Massachusetts Division.

\section{References}

Albrecht-Buehler, G. and Bushnell, A. 1980. The ultrastructure of primary cilia in quiescent $3 \mathrm{~T} 3$ cells. Exp. Cell Res. 126: $427-437$.

Alvey, P.L. 1985. An investigation of the centriole cycle using 3T3 and CHO cells. J. Cell Sci. 78: 147-162.

Aubin, J.E., Osborn, M., and Weber, K. 1980. Variations in the distribution and migration of centriole duplexes in mitotic $\mathrm{PtK}_{2}$ cells studied by immunofluorescence microscopy. I. Cell Sci. 43: 177-194.

Balczon, R., Bao, L., Zimmer, W.E., Brown, K., Zinkowski, R.P., and Brinkley, B.R. 1995. Dissociation of centrosome replication events from cycles of DNA synthesis and mitotic division in hydroxyurea-arrested Chinese hamster ovary cells. J. Cell Biol. 130: 105-115.

Balczon, R., Varden, C.E., and Schroer, T.A. 1999. Role for microtubules in centrosome doubling in Chinese hamster ovary cells. Cell Motil. Cytoskeleton 42: 60-72.

Bajer, A.S. 1982. Functional autonomy of monopolar spindle and evidence for oscillatory movement in mitosis. J. Cell Biol. 93: 33-48.

Bobinnec, Y., Khodjakov, A., Mir, L.M., Rieder, C.L., Edde, B., and Bornens, M. 1998. Centriole disassembly in vivo and its effect on centrosome structure and function in vertebrate cells. J. Cell Biol. 143: 1575-1589.

Bornens, M., Paintrand, M., Berges, J., Marty, M.C., and Karsenti, E. 1987. Structural and chemical characterization of isolated centrosomes. Cell Motil. Cytoskeleton 8: 238249.

Brinkley, B.R. 2001. Managing the centrosome numbers game: From chaos to stability in cancer cell division. Trends Cell Biol. 11: 18-21.

Carrano, A.C., Eytan, E., Hershko, A., and Pagano, M. 1999.
SKP2 is required for ubiquitin-mediated degradation of the CDK inhibitor p27. Nat. Cell Biol. 1: 193-199.

Carroll, P.E., Okuda, M., Horn, H.F., Biddinger, P., Stambrook, P.J., Gleich, L.L., Li, Y.Q., Tarapore, P., and Fukasawa, K. 1999. Centrosome hyperamplification in human cancer: Chromosome instability induced by p53 mutation and/or Mdm2 overexpression. Oncogene 18: 1935-1944.

Chiba, S., Okuda, M., Mussman, J.G., and Fukasawa, K. 2000. Genomic convergence and suppression of centrosome hyperamplification in primary $\mathrm{p} 53^{-/-}$cells in prolonged culture. Exp. Cell Res. 258: 310-321.

Compton, D.A. 2000. Spindle assembly in animal cells. Annu. Rev. Biochem. 69: 95-114.

Dietz, R. 1966. The dispensability of the centrioles in the spermatocyte divisions of Pales ferruginea (Nematocera). Heredity 19: 161-166.

Dippell, R.V. 1968. The development of basal bodies in paramecium. Proc. Natl. Acad. Sci. 61: 461-468.

Dirksen, E.R. 1991. Centriole and basal body formation during ciliogenesis revisited. Biol. Cell 72: 31-38.

Dutcher, S.K. 2001. The tubulin fraternity: Alpha to eta. Curr. Opin. Cell Biol. 13: 49-54.

Elledge, S.J. and Harper, J.W. 1994. Cdk inhibitors: on the threshold of checkpoints and development. Curr. Opin. Cell Biol. 6: 847-852.

Euteneuer, U. and McIntosh, J.R. 1981. Structural polarity of kinetochore microtubules in PtK1 cells. J. Cell Biol. 89: 338345.

Fenteany, G. and Schreiber, S.L. 1998. Lactacystin, proteasome function, and cell fate. J. Biol. Chem. 273: 8545-8548.

Freed, E., Lacey, K.R., Huie, P., Lyapina, S.A., Deshaies, R.J., Stearns, T., and Jackson, P.K. 1999. Components of an SCF ubiquitin ligase localize to the centrosome and regulate the centrosome duplication cycle. Genes \& Dev. 13: 2242-2257.

Fry, A.M., Mayor, T., Meraldi, P., Stierhof, Y.D., Tanaka, K. and Nigg, E.A. 1998. C-Nap1, a novel centrosomal coiled-coil protein and candidate substrate of the cell cycle-regulated protein kinase Nek2. J. Cell Biol. 141: 1563-1574.

Fukasawa, K., Choi, T., Kuriyama, R., Rulong, S., and Vande Woude, G.F. 1996. Abnormal centrosome amplification in the absence of p53. Science 271: 1744-1747.

Fulton, C. 1971. Centrioles. In Origin and continuity of cell organelles. (eds. C. Beerman, et al.), pp. 170-213. SpringerVerlag, New York.

Fulton C. and Dingle, A.D. 1971. Basal bodies, but not centrioles, in Naegleria. J. Cell Biol. 51: 826-836.

Gaglio, T., Dionne, M.A., and Compton, D.A. 1997. Mitotic spindle poles are organized by structural and motor proteins in addition to centrosomes. J. Cell Biol. 138: 1055-1066.

Gard, D.L., Hafezi, S., Zhang, T. and Doxsey, S.J. 1990. Centrosome duplication continues in cycloheximide-treated Xenopus blastulae in the absence of a detectable cell cycle. J. Cell Biol. 110: 2033-2042.

Gallant, P. and Nigg, E.A. 1992. Cyclin B2 undergoes cell cycledependent nuclear translocation and, when expressed as a non-destructible mutant, causes mitotic arrest in HeLa cells. J. Cell Biol. 117: 213-224.

Giet, R. and Prigent, C. 1999. Aurora/Ipllp-related kinases, a new oncogenic family of mitotic serine-threonine kinases. $J$. Cell Sci. 112: 3591-3601.

Glotzer, M., Murray, A.W., and Kirschner, M.W. 1991. Cyclin in degraded by the ubiquitin pathway. Nature 349: 132-138.

Glover, D.M., Hagan, I.M., and Tavares, A.A. 1998. Polo-like kinases: A team that plays throughout mitosis. Genes \& Dev. 12: 3777-3787.

Goepfert, T.M. and Brinkley, B.R. 2000. The centrosome-asso- 
ciated Aurora/Ipl-like kinase family. Curr. Top Dev. Biol. 49: 331-342.

Gould, R.R. 1975. The basal bodies of Chlamydomonas reinhardtii: Formation from probasal bodies, isolation, and partial characterization. J. Cell Biol. 65: 65-74.

Gould, R.R. and Borisy, G.G. 1977. The pericentriolar material in Chinese hamster ovary cells nucleates microtubule formation. J. Cell Biol. 73: 601-615.

Gstaiger, M., Marti, A., and Krek, W. 1999. Association of human SCF(SKP2) subunit p19(SKP1) with interphase centrosomes and mitotic spindle poles. Exp. Cell Res. 247: 554562.

Hartley, R.S., Sible, J.C., Lewellyn, A.L., and Maller, J.L. 1997. A role for cyclin $\mathrm{E} / \mathrm{Cdk} 2$ in the timing of the midblastula transition in Xenopus embryos. Dev. Biol. 188: 312-321.

Heald, R., Tournebize, R., Blank, T., Sandaltzopoulos, R., Becker, P., Hyman, A., and Karsenti, E. 1996. Self-organization of microtubules into bipolar spindles around artificial chromosomes in Xenopus egg extracts. Nature 382: 420 425.

Heald, R., Tournebize, R., Habermann, A., Karsenti, E., and Hyman, A. 1997. Spindle assembly in Xenopus egg extracts: Respective roles of centrosomes and microtubule self-organization. J. Cell Biol. 138: 615-628.

Heneen, W.K. 1975. Kinetochores and microtubules in multipolar mitosis and chromosome orientation. Exp. Cell Res. 91: 57-62.

Hepler, P.K. 1976. The blepharoplast of Marsilea: Its de novo formation and spindle association. J. Cell Sci. 21: 361-390.

Hinchcliffe, E.H., Cassels, G.O., Rieder, C.L., and Sluder, G. 1998. The coordination of centrosome reproduction with nuclear events during the cell cycle in the sea urchin zygote. J. Cell Biol. 140: 1417-1426.

Hinchcliffe, E.H. and Linck, R.W. 1998. Two proteins isolated from sea urchin sperm flagella: Structural components common to the stable microtubules of axonemes and centrioles. J. Cell Sci. 111: 585-595.

Hinchcliffe, E.H. and Sluder, G. 1998. The apparent linkage between centriole replication and $\mathrm{S}$ phase of the cell cycle. Cell Biol. Int. 22: 3-5.

Hinchcliffe, E.H., Li, C., Thompson, E.A., Maller, J.L., and Sluder, G. 1999. Requirement of Cdk2-cyclin E activity for repeated centrosome reproduction in Xenopus egg extracts. Science 283: 851-854.

Hinchcliffe, E.H., Miller, F.J., Cham, M., Khodjakov, A., and Sluder, G. 2001. Requirement of a centrosomal activity for cell cycle progression through $G_{1}$ into $S$ phase. Science 291: $1547-1550$.

Holloway, S., Glotzer, M., King, R.W., and Murray, A.W. 1993. Anaphase is initiated by proteolysis rather than by the inactivation of maturation-promoting factor. Cell 73: 13931402.

Jackson, P.K., Chevalier, S., Philippe, M., and Kirschner, M.W. 1995. Early events in DNA replication require cyclin E and are blocked by p21CIP1. J. Cell Biol. 130: 755-769.

Jackson, P.K., Eldridge, A.G., Freed, E., Furstenthal, L., Hsu, J.Y., Kaiser, B.K., and Reimann, J.D. 2000. The lore of the RINGs: Substrate recognition and catalysis by ubiquitin ligases. Trends Cell Biol. 10: 429-439.

Jiang, J. and Struhl, G. 1998. Regulation of the hedgehog and wingless signaling pathways by the F-box/WD40-repeat protein Slimb. Nature 391: 493-496.

Kallenbach, R.J. and Mazia, D. 1982. Origin and maturation of centrioles in association with the nuclear envelope in hypertonic-stressed sea urchin eggs. Eur. J. Cell Biol. 28: 68-76.

Khodjakov, A., Cole, R.W., Oakley, B.R., and Rieder, C.L. 2000.
Centrosome-independent mitotic spindle formation in vertebrates. Curr. Biol. 10: 59-67.

Khodjakov, A. and Rieder, C.L. 2001. Centrosomes enhance the fidelity of cytokinesis in vertebrates and are required for cell cycle progression. J. Cell Biol. 153: 247-252.

King, R.W., Deshaies, R.J., Peters, J.-M., and Kirschner, M.W. 1996. How proteolysis drives the cell cycle. Science 274: 1652-1659.

Kochanski, R.S. and Borisy, G.G. 1990. Mode of centriole duplication and distribution. J. Cell Biol. 110: 1599-1605.

Kuriyama, R. and Borisy, G.G. 1981. Centriole cycle in Chinese hamster ovary cells as determined by whole-mount electron microscopy. J. Cell Biol. 91: 814-821.

Lacey, K.R., Jackson, P.K., and Stearns, T. 1999. Cyclin-dependent kinase control of centrosome duplication. Proc. Natl. Acad. Sci. 96: 2817-2822.

Lange, B.M., Faragher, A.J., March, P., and Gull, K. 2000. Centriole duplication and maturation in animal cells. Curr. Top. Dev. Biol. 49: 235-249.

Lingle, W.A., Lutz, W.H., Ingle, J.N., Maihle, N.J., and Salisbury, J.L. 1998. Centrosome hypertrophy in human breast tumors: Implications for genomic stability and cell polarity. Proc. Nat1. Acad. Sci. 95: 2950-2955.

Lutz, W., Lingle, W.L., McCormick, D., Greenwood, T.M., and Salisbury, J.L. 2001. Phosphorylation of centrin during the cell cycle and its role in centriole separation preceding centrosome duplication. J. Biol. Chem. Mar 12; (publ. on-line ahead of print).

Mack, G. and Rattner, J.B. 1993. Centrosome repositioning immediately following karyokinesis and prior to cytokinesis. Cell Motil. Cytoskeleton 26: 239-247.

Maller, J., Poccia, D., Nishioka, D., Kidd, P., Gerhart, J., and Hartman, H. 1976. Spindle formation and cleavage in Xenopus eggs injected with centriole-containing fractions from sperm. Exp. Cell Res. 99: 285-294.

Maniotis, A. and Schliwa, M. 1991. Microsugical removal of centrosomes blocks cell reproduction and centriole generation in BSC-1 cells. Cell 67: 495-504.

Marshall, W.F. and Rosenbaum, J.L. 1999. Cell division: The renaissance of the centriole. Curr. Biol. 9: R218-R220.

- 2000. Are there nucleic acids in the centrosome? Curr. Top. Dev. Biol. 49: 187-205.

Mathias, N., Johnson, S.L., Winey, M., Adams, A.E., Goetsch, L., Pringle, J.R., Byers, B., and Goebl, M.G. 1996. Cdc53p acts in concert with Cdc4p and Cdc34p to control the G1-to-Sphase transition and identifies a conserved family of proteins. Mol. Cell Biol. 16: 6634-6643.

Matsumoto, Y., Hayashi, K., and Nishida, E. 1999. Cyclin-dependent kinase $2(\mathrm{Cdk} 2)$ is required for centrosome duplication in mammalian cells. Curr. Biol. 9: 429-432.

Mayor, T., Stierhof, Y.D., Tanaka, K., Fry, A.M., and Nigg, E.A. 2000. The centrosomal protein C-Nap1 is required for cell cycle-regulated centrosome cohesion. J. Cell Biol. 151: 837846.

Mazia, D. 1987. The chromosome cycle and the centrosome cycle in the mitotic cycle. Int. Rev. Cytol. 100: 49-92.

Mazia, D., Harris, P., and Bibring, T. 1960. The multiplicity of the mitotic centers and the time-course of their duplication and separation. Biophys. Biochem. Cytol. 7: 1-20.

McDonnell, H.B. and Byers, B. 1997. A proteosome cap subunit required for spindle pole body duplication in yeast. J. Cell Biol. 137: 539-553.

Meraldi, P., Lukas, J., Fry, A.M., Bartek, J., and Nigg, E.A. 1999. Centrosome duplication in mammalian somatic cells requires E2F and Cdk2-Cyclin A. Nat. Cell Biol. 1: 88-93.

Murray, A.W. and Kirschner, M.W. 1989. Cyclin synthesis 
drives the early embryonic cell cycle. Nature 339: 275-280.

Mussman, J.G., Horn, H.F., Carroll, P.E., Okuda, M., Tarapore, P., Donehower, L.A., and Fukasawa, K. 2000. Synergistic induction of centrosome hyperamplification by loss of $\mathrm{p} 53$ and cyclin E overexpression. Oncogene 19: 1635-1646.

Nakayama, K., Nagahama, H., Minamishima, Y.A., Matsumoto, M., Nakamichi, I., Kitagawa, K., Shirane, M., Tsunematsu, R., Tsukiyama, T., Ishida, N., et al. 2000. Targeted disruption of Skp2 results in accumulation of cyclin $\mathrm{E}$ and p27(Kip1), polyploidy and centrosome overduplication. EMBO J. 19: 2069-2081.

Okuda, M., Horn, H.F., Tarapore, P., Tokuyama, Y., Smulian, A.G., Chan, P.K., Knudsen, E.S., Hofmann, I.A., Snyder, J.D., Bove, K.E., et al. 2000. Nucleophosmin/B23 is a target of Cdk2/cyclin E in centrosome duplication. Cell 103: 127140.

Orr-Weaver, T.L. and Weinberg, R.A. 1998. A checkpoint on the road to cancer. Nature 392: 223-224.

Piel, M., Meyer, P., Khodjakov, A., Rieder, C.L., and Bornens, M. 2000. The respective contributions of the mother and daughter centrioles to centrosome activity and behavior in vertebrate cells. J. Cell Biol. 149: 317-330.

Piel, M., Nordberg, J., Euteneuer, U., and Bornens, M. 2001. Centrosome-dependent exit of cytokinesis in animal cells. Science 291: 1550-1553.

Peter, M., Nakagawa, J., Doree, M., Labbe, J.C., and Nigg, E.A. 1990. Identification of major nucleolar proteins as candidate mitotic substrates of cdc2 kinase. Cell 60: 791-801.

Pihan, G.A., Purohit, A., Wallace, J., Knecht, H., Woda, B., Quesenberry, P., and Doxsey, S.J. 1998. Centrosome defects and genetic instability in malignant tumors. Cancer Res. 58: 3974-3985.

Preble, A.M., Giddings, T.M., and Dutcher, S.K. 2000. Basal bodies and centrioles: their function and structure. Curr. Top Dev. Biol. 49: 207-233.

Purohit, A., Tynan, S.H., Vallee, R., and Doxsey, S.J. 1999. Direct interaction of pericentrin with cytoplasmic dynein light intermediate chain contributes to mitotic spindle organization. J. Cell Biol. 147: 481-492.

Raff, J.W. and Glover, D.M. 1988. Nuclear and cyctoplasmic mitotic cycles continue in Drosophila embryos in which DNA synthesis is inhibited by aphidicolin. I. Cell Biol. 107: 2009-2019.

Rattner, J.B. and Phillips, S.A. 1976. Dependence of centriole formation on protein synthesis. J. Cell Biol. 70: 9-19.

Rempel, R.E., Sleight, S.B., and Maller, J.L. 1995. Maternal Xenopus Cdk2-cyclin E complexes function during meiotic and early embryonic cell cycles that lack a $G_{1}$ phase. J. Biol. Chem. 270: 6843-6855.

Rieder, C.L. 1990. Formation of the astral mitotic spindle: ultrastructural basis for the centrosome-kinetochore interaction. Electron Microsc. Rev. 3: 269-300.

Rieder, C.L. and Borisy, G.G. 1982. The centrosome cycle in $\mathrm{PtK}_{2}$ cells: Asymmetric distribution and structural changes in the pericentriolar material. Biol. Cell 44: 117-132.

Ring, D., Hubble, R., and Kirschner, M. 1982. Mitosis in a cell with multiple centrioles. J. Cell Biol. 94: 549-556.

Robbins, E.L., Jentzsch, G., and Micali, A. 1968. The centriole cycle in synchronized HeLa cells. J. Cell Biol. 36: 329-339.

Salisbury, J.L. 1995. Centrin, centrosomes, and mitotic spindle poles. Curr. Opin. Cell Biol. 7: 39-45.

Schmidt-Zachmann, M. S., Hugle-Dorr, B., and Franke, W.W. 1987. A constitutive nucleolar protein identified as a member of the nucleoplasmin family. EMBO J. 6: 1881-1890.

Schnackenberg, B.J. and Palazzo, R.E. 1999. Identification and function of the centrosome centromatrix. Biol. Cell 91:
$429-438$.

Singer, J.D., Gurian-West, M., Clurman, B., and Roberts, J.M. 1999. Cullin-3 targets cyclin E for ubiquitination and controls S phase in mammalian cells. Genes \& Dev. 13: 23752387.

Sharp, D.J., Rogers, G.C., and Scholey, J.M. 2000. Microtubule motors in mitosis. Nature 407: 41-47.

Sluder, G. and Begg, D.A. 1985. Experimental analysis of the reproduction of spindle poles. J. Cell Sci. 76: 35-51.

Sluder, G. and Rieder, C.L. 1985. Centriole number and the reproductive capacity of spindle poles. J. Cell Biol. 100: 887896.

Sluder, G. and Lewis, K. 1987. Relationship between nuclear DNA synthesis and centrosome reproduction in sea urchin eggs. J. Exp. Zoology 244: 89-100.

Sluder, G., Miller, F.J., and Rieder, C.L. 1986. The reproduction of centrosomes: Nuclear versus cytoplasmic controls. J. Cell Biol. 103: 1873-1881.

1989. Reproductive capacity of sea urchin centrosomes without centrioles. Cell Motil Cytoskeleton 13: 264-273.

Sluder, G., Miller, F.J., Cole, R., and Rieder, C.L. 1990. Protein synthesis and the cell cycle: Centrosome reproduction in sea urchin eggs is not under Translational control. J. Cell Biol. 110: 2025-2032.

Sluder, G., Thompson, E.A., Miller, F.J., Hayes, J., and Rieder, C.L. 1997. The checkpoint control for anaphase onset does not monitor excess numbers of spindle poles or bipolar spindle symmetry. J. Cell Sci. 110: 421-429.

Sorokin, S.P. 1968. Reconstructions of centriole formation and ciliogenesis in mammalian lungs. J. Cell Sci. 3: 207-230.

Spruck, C.H., Won, K.A., and Reed, S.I. 1999. Deregulated cyclin E induces chromosome instability. Nature 401: 297-300.

Steffen, W., Fuge, H., Dietz, R., Bastmeyer, M., and Muller, G. 1986. Aster-free spindle poles in insect spermatocytes: evidence for chromosome-induced spindle formation? J. Cell Biol. 102: 1679-1687.

Steffen, W., Fajer, E.A., and Linck, R.W. 1994. Centrosomal components immunologically related to tektins from ciliary and flagellar microtubules. J. Cell Sci. 107: 2095-2105.

Strausfeld, U.P., Howell, M., Descombes, P., Chevalier, S., Rempel, R., Adamczewski, J., Maller, J.L., Hunt, T., and Blow, J.J. 1996. Both cyclin A and cyclin E have S-phase promoting (SPF) activity in Xenopus egg extracts. J. Cell Sci. 109: 15551563.

Stubblefield, E. 1968. Centriole replication in mammalian cells. In The proliferation and spread of neoplastic cells: A collection of papers from the 21st Symposium on Fundamental Cancer Research pp. 185-203. Williams and Wilkins, Baltimore.

Su, J.-Y., Rempel, R.E., Erikson, E., and Maller, J.L. 1995. Cloning and characterization of the Xenopus cyclin-dependant kinase inhibitor $\mathrm{p} 27^{\mathrm{XIC1}}$. Proc. Natl. Acad. Sci. 92: 1018710191.

Szollosi, D., Calarco, P., and Donahue, R.P. 1972. Absence of centrioles in the first and second meiotic spindles of mouse oocytes. J. Cell Sci. 11: 521-541.

Tucker, R.W., Pardee, A.B., and Fujiwara, K. 1979. Centriole ciliation is related to quiescence and DNA synthesis in 3T3 cells. Cell 17: 527-535.

Tugendreich, S., Tomkiel, J., Earnshaw, W., and Hieter, P. 1995. $\mathrm{CDC} 27 \mathrm{Hs}$ colocalizes with $\mathrm{CDC} 16 \mathrm{Hs}$ to the centrosome and mitotic spindle and is essential for the metaphase to anaphase transition. Cell 81: 261-268.

Vidwans, S.J., Wong, M.L., and O'Farrell, P.H. 1999. Mitotic regulators govern progress through steps in the centrosome duplication cycle. J. Cell Biol. 147: 1371-1378. 
Von Ledebur-Villiger, M. 1972. Cytology and nucleic acid synthesis of parthenogenetically activated sea urchin eggs. Exp. Cell Res. 72: 285-308.

Vorobjev, I.A. and Chentsov, Y.S. 1982. Centrioles in the cell cycle. I. Epithelial cells. J. Cell Biol. 93: 938-949.

Vorobjev, I.A., and Nadezhdina, E.S. 1987. The centrosome and its role in the organization of microtubules. Int. Rev. Cytol. 106: 227-293.

Wang, Y., Penfold, S., Tang, X., Hattori, N., Riley, P., Harper, J.W., Cross, J.C., and Tyers, M. 1999. Deletion of the Cull gene in mice causes arrest in early embryogenesis and accumulation of cyclin E. Curr. Biol. 9: 1191-1194.

Wheatley, D.N. 1982. The centriole: A central enigma of cell biology. Elsevier Biomedical Press, Amsterdam.

Wheatley, D.N., Wang, A.M., and Strugnell, G.E. 1996. Expression of primary cilia in mammalian cells. Cell Biol. Int. 20: 73-81.

Wiese, C. and Zheng, Y. 1999. $\gamma$ Tubulin complexes and their interaction with microtubule-organizing centers. Curr. Opin. Struct. Biol. 9: 250-259.

Wigley, W.C., Fabunmi, R.P., Lee, M.G., Marino, C.R., Muallem, S., DeMartino, G.N., and Thomas, P.J. 1999. Dynamic association of proteasomal machinery with the centrosome. J. Cell Biol. 145: 481-490.

Wilson, E.B. 1896. The cell in development and inheritance. Columbia University Press, New York.

Winey, M. 1999. Cell cycle: Driving the centrosome cycle. Curr. Biol. 9: R449-R452.

Winston, J.T., Chu, C., and Harper, J.W. 1999. Culprits in the degradation of cyclin E apprehended. Genes \& Dev. 13: 2751-2757.

Wojcik, E.J., Glover, D.M., and Hays, T.S. 2000. The SCF ubiquitin ligase protein slimb regulates centrosome duplication in drosophila. Curr. Biol. 10: 1131-1134.

Zachariae, W. and Nasmyth, K. 1999. Whose end is destruction: Cell division and the anaphase-promoting complex. Genes \& Dev. 13: 2039-2058.

Zatsepina, O.V., Rousselet, A., Chan, P.K., Olson, M.O., Jordan, E.G., and Bornens, M. 1999. The nucleolar phosphoprotein B23 redistributes in part to the spindle poles during mitosis. J. Cell Sci. 112: 455-466.

Zhou, H., Kuang, J., Zhong, L., Kuo, W.L., Gray, J.W., Sahin, A., Brinkley, B.R., Sen, S. 1998. Tumour amplified kinase STK15/BTAK induces centrosome amplification, aneuploidy and transformation. Nat. Genet. 20: 189-193.

Zimmerman, W., Sparks, C.A., and Doxsey, S.J. 1999. Amorphous no longer: The centrosome comes into focus. Curr. Opin. Cell Biol. 11: 122-128. 


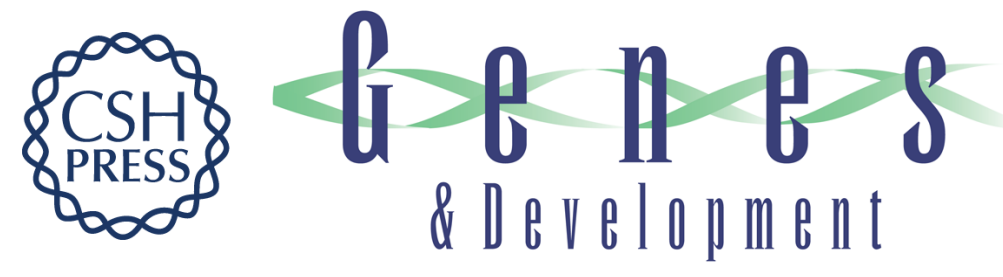

\title{
"It Takes Two to Tango": understanding how centrosome duplication is regulated throughout the cell cycle
}

\author{
Edward H. Hinchcliffe and Greenfield Sluder
}

Genes Dev. 2001, 15:

Access the most recent version at doi:10.1101/gad.894001

$\begin{array}{ll}\text { References } & \begin{array}{l}\text { This article cites } 122 \text { articles, } 63 \text { of which can be accessed free at: } \\ \text { http://genesdev.cshlp.org/content/15/10/1167.full.html\#ref-list-1 }\end{array}\end{array}$

License

Email Alerting Receive free email alerts when new articles cite this article - sign up in the box at the top Service right corner of the article or click here.

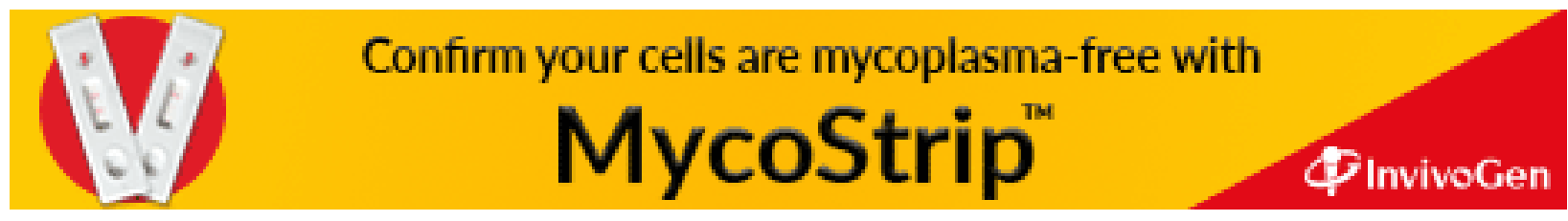

